\title{
Comparison of weather radar, numerical weather prediction and gauge-based rainfall estimates
}

\author{
$\underline{\text { M. Shahrban }}^{\text {a,b }}$, J.P. Walker ${ }^{\mathrm{a}}$, Q.J. Wang ${ }^{\mathrm{b}}$, A. Seed ${ }^{\mathrm{c}}$ and P. Steinle ${ }^{\mathrm{c}}$ \\ ${ }^{a}$ Department of Civil Engineering, Monash University, Australia \\ ${ }^{b}$ CSIRO Land and Water, Australia \\ ${ }^{c}$ Center for Australian Weather and Climate, Bureau of Meteorology, Australia \\ Email: mahshid.shahrban@monash.edu
}

\begin{abstract}
Hydrological hazards have been extensive world-wide in recent times. In particular, there has been widespread flooding across much of Australia in response to extreme precipitation events. Hydrological modelling can be used to effectively manage the extensive effects of flood events, but the primary input for hydrological hind-, now- and fore-casting of these events is reliable knowledge of both observed and forecast precipitation.
\end{abstract}

The Bureau of Meteorology's rain gauge network is the most common source of data on precipitation in Australia, and is the benchmark for validation of other estimates, despite its limitations. However, the rain gauge network is spatially limited for much of Australia, with interpolation commonly required. Moreover, the uncertainty of these estimates increases with distance from the gauge, there can be significant lag times in receiving the data (especially from daily gauges), and they give no indication of the likely precipitation in the coming hours. In contrast, weather radars present the opportunity to measure precipitation data with good spatial and temporal resolution. However, weather radars require repeated adjustment against the gauge network to decrease their inaccuracies. In addition, the accuracy of the rainfall declines with distance from the radar, because the radar scans are too high to see low-level precipitation at far range. Moreover, there is limited spatial coverage by quantitative weather radars in Australia, which are mostly located near the capital cities and along the eastern coastline. Numerical weather prediction (NWP) models can provide information on precipitation with national coverage for different spatial and temporal resolutions with lead times out to several days, but the accuracy of this information is uncertain. This uncertainty is due to high variability of rainfall in space and time, and the inadequacy of current numerical weather prediction physics. Many studies have focused on developing effective methods for error estimation of these predictions, because of the considerable potential for its use in hydrologic applications, but have been limited to individual storms. Consequently, the best estimation of precipitation data for flood forecasting in Australia is likely to include a combination of all three approaches (gauge network, weather radar observations and nowcasts, together with numerical weather prediction forecasts), but the uncertainty in each must be understood through longitudinal studies using independent precipitation data.

This paper undertakes an extensive inter-comparison of these approaches using NWP outputs from the Australian Community Climate Earth-System Simulator (ACCESS) and the Yarrawonga radar data, using an independent rain gauge network in the Murrumbidgee catchment in south eastern Australia. Several statistical comparisons were made using hourly and daily accumulation of rainfall from January to August 2010 to estimate the errors between radar/NWP and the gauge network, with results presented for one representative station. It was found that the radar has fewer "false alarms" than NWP (26\% versus $74 \%$ for hourly rainfall). Most large errors for radar and NWP estimates were found to occur between Feb-April, which can be related to the particular weather events in these months. Based on average value of bias, radar mostly underestimated rainfall with the largest difference from gauge measurements in March $(-0.78 \mathrm{~mm} / \mathrm{hr}$ and $-3.44 \mathrm{~mm} / \mathrm{day}$ for hourly and daily data accumulations respectively) while NWP mostly overestimated the rainfall (0.07-0.09 $\mathrm{mm} / \mathrm{hr}$ and $0.64-0.89 \mathrm{~mm} /$ day). Moreover, NWP with 12-24 and 24-36hr lead times $(0.97 \mathrm{~mm} / \mathrm{hr}$ and 3.39 $\mathrm{mm}$ /day RMSE for hourly and daily accumulations respectively) outperformed the 0-12 and 36-48hr lead times, while radar had larger errors $(1.38 \mathrm{~mm} / \mathrm{hr}$ and $4.17 \mathrm{~mm} /$ day for hourly and daily accumulations respectively). It should be noted that the gauge station was located a large distance from the radar, potentially leading to larger than usual errors. Additionally, comparison of a single point gauge rainfall estimate may also exaggerate the errors from NWP which has a coarse resolution of $12 \mathrm{~km}$. Moreover, the usefulness of radar data in hydrological modelling is limited by the radar coverage for this catchment, the large amount of missing data, and the relatively poor performance compared to the model predictions. However, it is recommended that further studies of radar and model predictions be carried out for large experimental areas.

Keywords: gauge network, weather radars, numerical weather prediction, rainfall uncertainty 


\section{INTRODUCTION}

Floods have contributed worldwide destruction in recent times. In particular, there has been widespread flooding across much of Australia in response to extreme precipitation events during the past year. Hydrological modelling can help to manage the destructive consequences of such extensive flood events, providing it can forecast the events with sufficient lead time and accuracy.

Among the different input data required, reliable precipitation data play a crucial role in hydrological hind-, now- and fore-casting of these events. Rain gauge networks are the most common source of data on precipitation, and despite its limitations, can be considered as the gold-standard for validation of other sources of precipitation data, including satellite, weather radar and numerical weather prediction (NWP) products. While individual gauges cannot represent the spatial distribution of rainfall over a watershed, there are many techniques to convert individual gauge data to spatial estimates, including arithmetical average, Thiessen polygon and the isohyets methods. However, the uncertainty of these estimates increases with distance from the gauge, and consequently with reduction in gauge density. The rain gauge network is spatially limited for much of Australia and interpolation is performed by the Bureau of Meteorology (BoM) as part of the Australian Water Availability Project (AWAP). Spatial analyses of in situ rainfall were developed by AWAP to provide Australia-wide gridded $\left(0.05^{\circ} \times 0.05^{\circ}\right)$ daily rainfall. Additionally, there can be significant lag times in receiving the data, meaning even greater uncertainty in near-real-time precipitation estimates, making it difficult to use this data for forecasting purposes. Weather radars present the opportunity to measure precipitation with good spatial $(1 \mathrm{~km})$ and temporal $(10 \mathrm{~min})$ resolution. The procedure for estimating rainfall from weather radar consists of measuring the reflectivity followed by conversion to a rainfall rate using empirical formulae that are adjusted by calibration to a near-real-time rain gauge network. Numerical weather prediction models provide an alternative source of information on precipitation, with good spatial and temporal resolution and the added advantage of lead times out to several days. The modeled information is also routinely validated against rain gauges and such skill scores are based on prediction of individual events. Consequently, longitudinal studies of precipitation accuracy for radar and NWP estimates must be undertaken using independent data. Because the accuracy of NWP is uncertain, due to the highly variable nature of rainfall in space and time, techniques are being developed to undertake short-term high spatial resolution precipitation forecasting that combines the (perceived) skill of weather radar observations with the forecasting skill of NWP. However, this product is not evaluated in this paper as it is still under development by the BoM.

Quantification of rainfall uncertainty has been a controversial subject in hydrological studies, with many examples where hydrologists have validated estimates of radar and NWP precipitation estimates using rain gauge measurements. For example, Byung et al. (2008) evaluated different rainfall estimation methods for flood forecasting and found that conditional merging is the best method for combining radar and gauge observations. Biggs and Atkinson (2011) assessed the accuracy of the different precipitation data using universal cokriging to correct radar estimation, and concluded that gauge-corrected radar data predicted river flow with higher accuracy than raw radar data. These studies have not assessed the rainfall error per se, but rather the resultant stream flow forecasts. McBride and Ebert (2000) verified real-time gridded 24-h quantitative precipitation forecasts from seven operational NWP models against an operational daily rainfall analysis. These verifications were carried out over individual months, as well as for the summer and winter seasons. McPhee and Margulis (2005) validated a $1^{\circ}$ daily (GPCP-1DD) precipitation product over the contiguous United States, using daily gauge-based precipitation values. They showed that based on RMSE values, differences in precipitation estimates for individual $1^{\circ}$ cells mostly exceeded the magnitude of the average precipitation. Consequently, this paper will undertake an independent evaluation of precipitation products using gauge rainfall data for an extended period of time. Verification statistics including probability of detection, false alarm ratio, bias and root mean square error were used to investigate the consistency of rainfall measurements derived from the Yarrawonga weather radar as well as the BoM NWP forecasts in the Murrumbidgee catchment using independent gauge precipitation data from the OzNet monitoring stations as ground truth.

\section{STUDY AREA}

The Murrumbidgee Catchment is a major sub-catchment of the Murray Darling Basin (MDB) in southern New South Wales (Figure 1). The drainage area of the catchment is around $84,000 \mathrm{~km}^{2}$ and the main river is approximately $1600 \mathrm{~km}$ in length. The climate in the Murrumbidgee catchment varies from semiarid in the west to alpine in the east. The mean annual rainfall in the region is $300 \mathrm{~mm}$ in the west and $1900 \mathrm{~mm}$ in the east. The catchment covers 8.2 percent of the Murray-Darling Basin contributing 15.7 percent of the total runoff. Major rain events during late 2010 caused substantial flooding in various parts of the south eastern parts of Australia. Importantly, the Murrumbidgee peaked at nearly10 metres in early December 2010 with several cities in the catchment experiencing their worst flooding since 1974 (ABARES, 2011). 


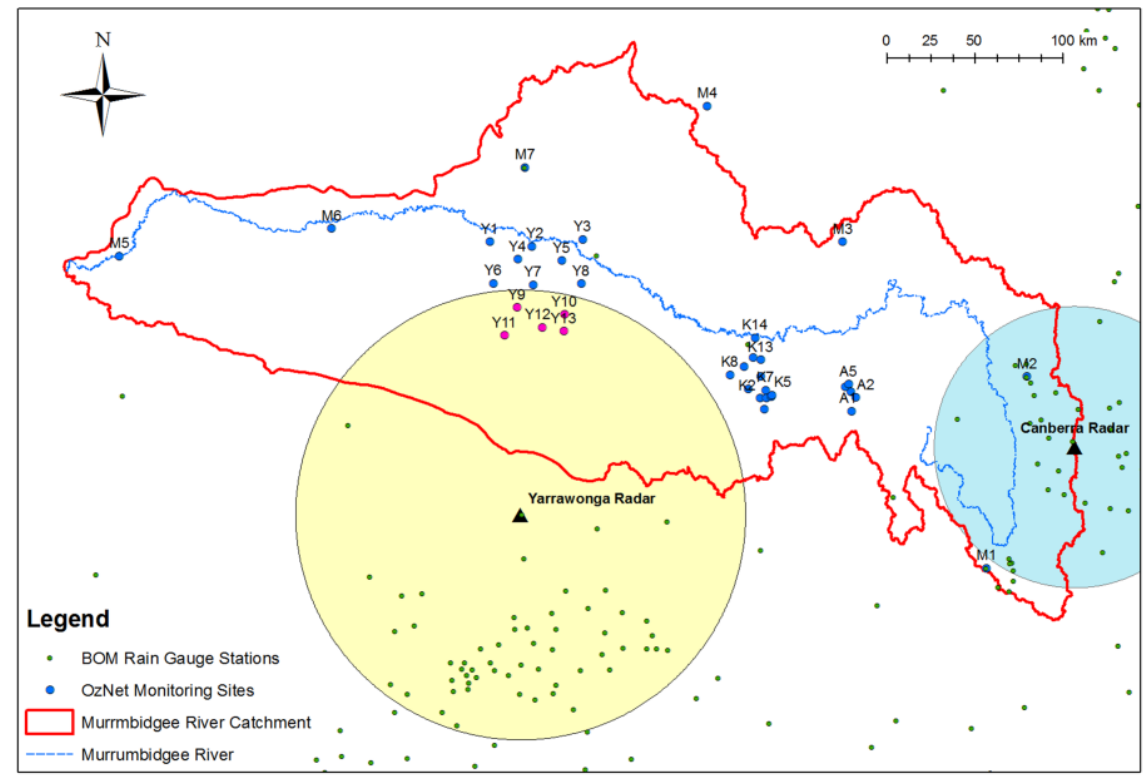

Figure 1: Location of OzNet and BoM automatic rainfall monitoring stations in the Murrumbidgee catchment and the two quantitative weather radars in the study area.

This study is focused on the Yanco region (Y sites in Figure 1), a $60 \mathrm{~km} \times 60 \mathrm{~km}$ area located in the western flat plains of the Murrumbidgee catchment, with the Murrumbidgee River immediately to the north of the area. Approximately one-third of the Yanco area is occupied by the Coleambally Irrigation Area (CIA), an agricultural area with more than 500 farms (Merlin et al., 2008). In addition to the meteorological importance of the catchment, several independent rain gauges are located in the catchment (Figure 1). These are the OzNet monitoring sites (http://www.oznet.org.au), jointly operated by Monash University and the University of Melbourne. Additionally, the study area is covered partially by two weather radars (Yarrawonga and Canberra).

\section{EXPERIMENTAL DATA}

The OzNet rain gauge data include 13 gauge monitoring stations in the Yanco area, located in the plains area of the Murrumbidgee catchment as shown in Figure 1. These tipping-bucket rain gauges recorded each tip of the $0.2 \mathrm{~mm}$ bucket. Radar rainfall data were provided by the BoM for the Yarrawonga radar at $1 \mathrm{~km}$ resolution for every 10 minutes, being one of the quantitative weather radars they operate in Australia. It is a C-band Doppler radar located in northern Victoria, with coverage of the southern portion of the Yanco study region. The 10 minute rainfall measurements were accumulated to hourly data for comparison with gauge and NWP estimates. Canberra (Captains Flat) is the other quantitative weather radar with coverage of the Murrumbidgee catchment. It has not been used for this study due to the fact that no independent rain gauges with less than daily accumulations are located within its coverage. The locations and coverage of these two radars is shown in Figure 1. The Yarrawonga radar rainfall data have been cleaned and calibrated by the BoM using the near-realtime gauge stations operated by the BoM as shown in Figure 1. For numerical weather prediction data, precipitation forecasts from the Australian Community Climate Earth-System Simulator (ACCESS-A) have been used for comparison with the gauge rainfall data. The ACCESS forecast system is based on an implementation of the Unified Modelling System (UMS) developed by the United Kingdom Met Office (UKMO) coupled with land surface, ocean and atmospheric modelling components that have been developed and tested in the Earth System Modelling Program for Australian Weather and Climate Research (CAWCR). This NWP product covers the entire Australian domain with a resolution of 0.11 degree (about $12 \mathrm{~km}$ ). The gridded precipitation forecasts are run four times per day with a lead time out to 2 days (BoM, 2010).

\section{RESULTS AND DISCUSSION}

Station Y10 in the Yanco area was selected as the representative station for an 8-month comparative study of the radar and NWP with gauge rainfall from January to August 2010. The results for this station have been selected for this paper as there is only a small difference in results among all stations. The first 8 months were chosen as 
the data of the next few months in 2010 were not processed and archived at the time of undertaking this analysis. Radar and gauge observations were accumulated to both hourly and daily values. Four different time series of hourly NWP data were obtained from forecasts using lead times of 0-12, 12-24, 24-36 and 36-48 hours. Each of the hourly time series were accumulated to daily precipitation and individually compared with hourly and daily gauge observations on the basis of the nearest neighbour.

Two types of comparison including categorical and continuous statistics can be made (McPhee et al., 2005). Probability of detection (POD) and false alarm ratio (FAR) were computed as the categorical statistics estimating the accuracy score of the data. Additionally, mean error (bias) and root mean square error (RMSE) were the continuous statistics calculated in this study. POD identifies the fraction of observed events that were correctly predicted by radar or model, and FAR indicates the fraction of predicted events that were observed to be nonevents. Their equations are (McBride et al., 2005)

$$
\begin{aligned}
& P O D=H /(H+M) \\
& F A R=F /(H+F),
\end{aligned}
$$

where $\mathrm{H}$ (hits) is the number of the actual rain events predicted by radar/model, $\mathrm{M}$ (misses) is the actual rainfall events missed by them and $\mathrm{F}$ (false alarm) is the non-observed rain predicted by radar/model. The results are presented in Table 2 . Threshold values of 0.1 to $10 \mathrm{~mm} /$ day are typically used in many studies to separate rain from no-rain events. In this study, the thresholds $0.05 \mathrm{~mm} / \mathrm{hr}$ and $1 \mathrm{~mm} /$ day were used at hourly and daily scales respectively. It can be seen from Table 1 that the POD and FAR have been improved for daily as compared to hourly results, especially for ACCESS. There was no significant change between ACCESS estimates with different lead times, and the average over the 4 time series is presented. Although 25 percent of the daily gauge rainfall is not measured by the radar, there is only 9 percent false rain in daily radar data. In contrast, on average only 10 percent of the daily gauge measurements was not predicted by the ACCESS model and the proportion of false alarms is 0.32 .

Continuous statistics of radar, NWP, and gauge data was carried out for each individual month as well as the entire 8-month period, on an hourly and daily accumulation basis. Bias and RMSE are computed as the average of differences between the precipitation values in the gauge station and the nearest grid to the gauge. Bias and RMSE is based only on those cases in which non-zero precipitation was observed by at least one of the data sources compared. This prevents the error statistics from being unduly influenced by the large number of nonraining periods. The Bias and RMSE for daily and hourly radar and NWP data during each month and the 8month period are listed in Tables 2 and 3. The number of hourly data missed by the radar is 743 in 8 months $(13 \%)$ with a mean of 3 missed hours per day and a median of 1 missed hour per day. To calculate the daily accumulated radar rainfall, the hourly radar missing values were assumed as zero where the previous and next radar values have observed no rain and the gauge also had no rainfall recorded. All remaining non-value radar data and their corresponding gauge values were removed from the daily analysis to decrease the number of days with no recorded value. It can be seen from Tables 2 and 3 that there is no clear trend in monthly Bias and RMSE during the 8 months for radar and NWP. However, most hourly and daily forecasts from ACCESS tended to have positive biases, indicating that ACCESS typically overestimates the precipitation, while the radar on average underestimated the rainfall. These bias estimates differ from those derived from BoM verification studies for the period November 2009 to March 2010, with an underestimation of -2.5 to $-3.2 \mathrm{~mm} / \mathrm{day}$ (BoM, 2010).

The poorest results in radar data can be seen in March where the RMSE has reached its maximum value. This can be related to the particular weather events in this month; the total rainfall measured by the gauge in March is $47 \mathrm{~mm}$ with an average intensity of $2 \mathrm{~mm} / \mathrm{hr}$, which is high relative to other months. Similar conditions with intense rainfall can be seen in Feb and May (total rainfall values of 54 and $53 \mathrm{~mm}$ ) where the errors in radar data were also relatively high. This suggests that radar errors increased with rainfall intensity. Additionally, the distribution of BoM gauges in the Yanco area for calibration of radar data is not uniform, with a particular bias to the south (see Figure 1). Therefore, radar calibration factors are likely not representing any special weather

Table 1: POD and FAR for hourly and daily accumulation of radar and ACCESS.

\begin{tabular}{ccccccc}
\hline & \multicolumn{2}{c}{ POD } & & \multicolumn{2}{c}{ FAR } \\
\cline { 2 - 3 } \cline { 6 - 6 } & Hourly & Daily & & Hourly & Daily \\
\hline Radar & 0.68 & 0.75 & & 0.26 & 0.09 \\
ACCESS & 0.62 & 0.90 & & 0.74 & 0.32
\end{tabular}


conditions in the Yanco area. Furthermore, the study gauge is located a large distance from the radar (more than $100 \mathrm{~km}$ ), and it is well known that the error of radar precipitation measurement increases with distance (Brandes et al., 1998; Sebastianelli et al., 2010). The RMSE for the ACCESS 12-24 hourly forecasts and ACCESS 24-36 daily forecasts were lower than those obtained for the two other forecasts. To evaluate the relative importance of the error arising from comparing a NWP pixel against a single gauge observation, the standard deviation of the data for 3 adjacent gauges (Y10, Y12 and Y13) was calculated and compared with the RMSE of the forecasts. The standard deviation, $1.12 \mathrm{~mm} / \mathrm{hr}$ and $3 \mathrm{~mm} /$ day, are a significant fraction of the RMSE, indicating that the gauge sampling error may be significantly contributing to the RMSE statistic. Therefore, comparison between a large area and a single rain gauge may constrain some errors to the NWP statistics due to the relatively coarse resolution of the ACCESS. The importance of horizontal resolution of NWP precipitation forecasts has been investigated by many researchers like Hay and Clark (2003), Robert et al.(2009) and Ghile and Schulze (2010).

A linear regression was fitted through the daily data to determine the dependency between radar/ACCESS data and gauge measurements (Figure 2). The radar is the least biased (compared with ACCESS) with a slope of 1.13 and coefficient of determination of 0.66. The ACCESS 24-36 hr forecast rainfall estimates are the least biased with a slope of 0.72 and coefficient of determination of 0.62 . These low $\mathrm{R}^{2}$ values suggest that there is no simple bias correction factor that can be applied to the ACCESS or radar precipitation to make it more suitable for operational modelling. However, if the outliers (shown as $\mathrm{x}$ in Figure 2) are removed from both data sets, the radar and ACCESS correction factors become 0.99 and 0.79 respectively and the $\mathrm{R}^{2}$ increases to 0.84 (for both cases).

Table 2: Average of bias ( $\mathrm{mm} / \mathrm{hr}$ and $\mathrm{mm} / \mathrm{day})$ between radar/ACCESS and gauge rainfall.

\begin{tabular}{|c|c|c|c|c|c|c|c|c|c|c|}
\hline \multirow[b]{2}{*}{ Month } & \multicolumn{2}{|c|}{ Radar } & \multicolumn{2}{|c|}{$\begin{array}{l}\text { Access } 0-12 \mathrm{hr} \\
\text { forecast }\end{array}$} & \multicolumn{2}{|c|}{$\begin{array}{l}\text { Access } 12-24 \mathrm{hr} \\
\text { forecast }\end{array}$} & \multicolumn{2}{|c|}{$\begin{array}{l}\text { Access } 24-36 \mathrm{hr} \\
\text { forecast }\end{array}$} & \multicolumn{2}{|c|}{$\begin{array}{l}\text { Access } 36-48 \mathrm{hr} \\
\text { forecast }\end{array}$} \\
\hline & Hourly & Daily* & Hourly & Daily & Hourly & Daily & Hourly & Daily & Hourly & Daily \\
\hline Jan. & 0.03 & 0.10 & 0.09 & 0.43 & 0.14 & 0.92 & 0.18 & 1.30 & 0.22 & 1.69 \\
\hline Feb. & -0.26 & -1.48 & 0.02 & 0.14 & 0.02 & -0.49 & 0.15 & 1.26 & -0.07 & -0.75 \\
\hline Mar. & -0.78 & -3.44 & -0.01 & -0.07 & 0.16 & 1.56 & 0.11 & 0.79 & 0.40 & 3.62 \\
\hline Apr. & 0.03 & 0.15 & 0.39 & 2.83 & 0.27 & 1.61 & 0.09 & 0.58 & 0.25 & 2.00 \\
\hline May. & 0.12 & 0.68 & 0.01 & 0.09 & -0.07 & -0.81 & 0.02 & 0.32 & 0.09 & 0.93 \\
\hline Jun. & 0.00 & 0.01 & 0.03 & 0.25 & 0.08 & 0.69 & 0.05 & 0.39 & 0.06 & 0.62 \\
\hline Jul. & -0.06 & -0.20 & 0.07 & 0.77 & 0.05 & 0.57 & 0.00 & 0.04 & -0.02 & -0.26 \\
\hline Aug. & 0.02 & 0.06 & 0.14 & 1.86 & 0.07 & 0.89 & 0.14 & 1.75 & 0.03 & 0.35 \\
\hline All months & -0.16 & -0.65 & 0.09 & 0.89 & 0.07 & 0.64 & 0.08 & 0.79 & 0.08 & 0.81 \\
\hline
\end{tabular}

Table 3: Average of RMSE ( $\mathrm{mm} / \mathrm{hr}$ and $\mathrm{mm} /$ day) between radar/ACCESS and gauge rainfall.

\begin{tabular}{|c|c|c|c|c|c|c|c|c|c|c|}
\hline \multirow[b]{2}{*}{ Month } & \multicolumn{2}{|c|}{ Radar } & \multicolumn{2}{|c|}{$\begin{array}{l}\text { Access } 0-12 \mathrm{hr} \\
\text { forecast }\end{array}$} & \multicolumn{2}{|c|}{$\begin{array}{c}\text { Access } 12-24 \mathrm{hr} \\
\text { forecast }\end{array}$} & \multicolumn{2}{|c|}{$\begin{array}{c}\text { Access } 24-36 h r \\
\text { forecast }\end{array}$} & \multicolumn{2}{|c|}{$\begin{array}{c}\text { Access } 36-48 \mathrm{hr} \\
\text { forecast }\end{array}$} \\
\hline & Hourly & Daily* & Hourly & Daily & Hourly & Daily & Hourl & Daily & Hourly & Daily \\
\hline Jan. & 0.12 & 0.10 & 0.34 & 1.37 & 0.38 & 2.46 & 0.51 & 3.30 & 0.45 & 3.50 \\
\hline Feb. & 1.72 & 4.91 & 1.43 & 5.10 & 1.58 & 6.80 & 1.79 & 6.72 & 1.56 & 6.21 \\
\hline Mar. & 2.48 & 9.16 & 1.56 & 6.62 & 1.19 & 3.55 & 2.40 & 2.56 & 2.96 & 10.52 \\
\hline Apr. & 0.58 & 1.31 & 2.15 & 11.52 & 1.86 & 6.41 & 0.68 & 2.96 & 0.92 & 6.03 \\
\hline May. & 1.25 & 3.57 & 0.82 & 1.46 & 0.80 & 2.12 & 0.77 & 1.44 & 0.94 & 2.95 \\
\hline Jun. & 0.44 & 0.62 & 0.14 & 0.47 & 0.30 & 2.05 & 0.25 & 1.62 & 0.29 & 2.26 \\
\hline Jul. & 0.93 & 1.19 & 0.76 & 2.03 & 0.79 & 2.52 & 0.70 & 1.57 & 0.73 & 1.95 \\
\hline Aug. & 0.52 & 1.90 & 0.45 & 3.45 & 0.37 & 2.05 & 0.56 & 4.06 & 0.32 & 1.24 \\
\hline All months & 1.38 & 4.17 & 1.08 & 5.38 & 0.97 & 3.83 & 1.04 & 3.39 & 1.15 & 4.74 \\
\hline
\end{tabular}

* Note: 743 hours of hourly data is missed by the radar in 8 months. The mean of missing data is 3 hours per day and the median is 1 hour per day. The daily accumulated radar rainfall is computed under the assumption that the hourly radar missing values should be zero where the values before and after the missing hours are zero in both the radar and gauge records. Then, all remaining non-value radar data and their corresponding gauge values were removed from the daily analysis. 

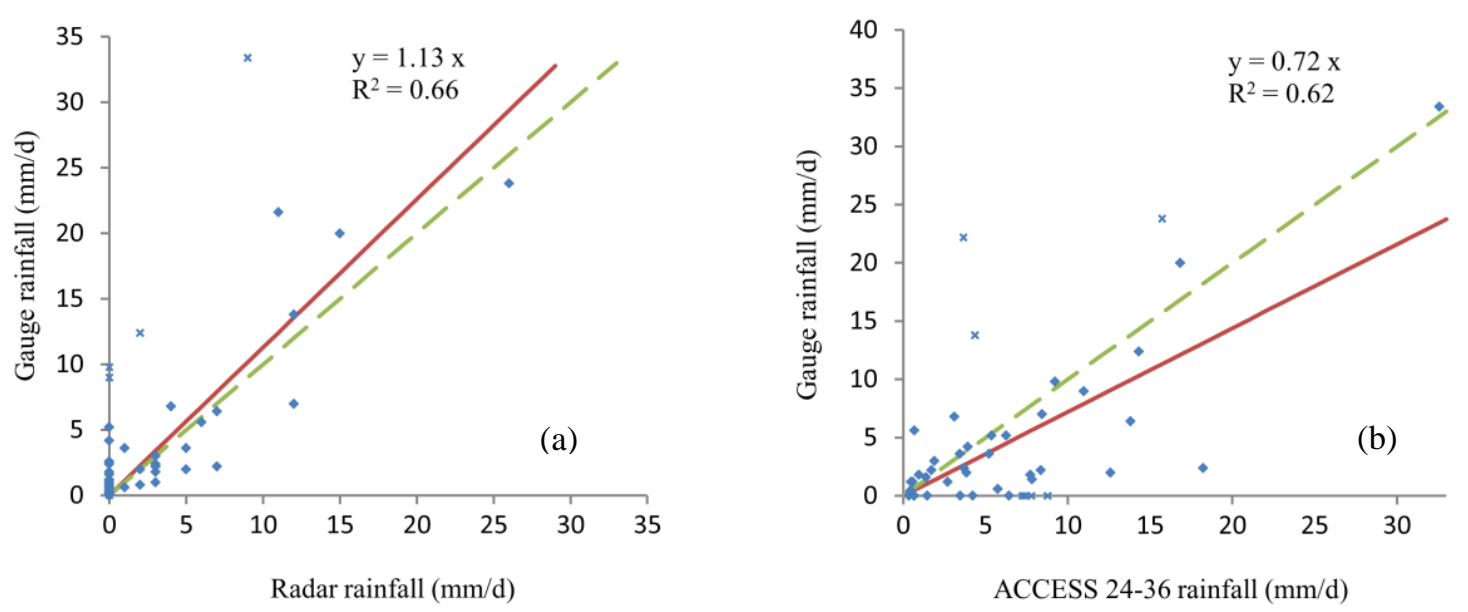

Figure 2: Scatter plots of a) daily radar and b) daily ACCESS against daily gauge data.
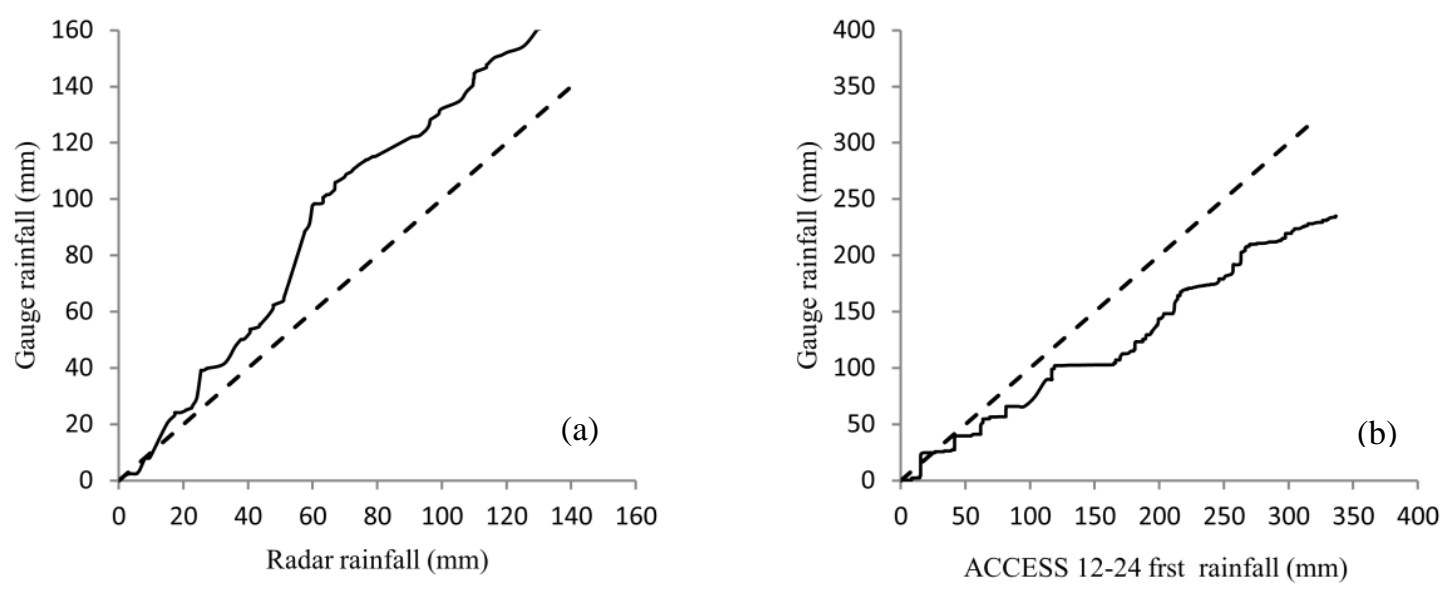

Figure 3: Comparison of hourly cumulative rainfall between gauge and a) radar and b) ACCESS.

Note that the difference in total gauge values obtained in these plots is due to the omission of gauge data during periods when there was no value available from the radar.

Double-mass curves have been used in order to characterize the consistency of the rainfall data. Figure 3 illustrates the double-mass curve for hourly cumulative values of radar and ACCESS rainfall against gauge data. The observed slope should be compared with the dashed line. The radar comparison revealed significant departure in March, where the gauge sum increased up to $98 \mathrm{~mm}$ as compared to only $60 \mathrm{~mm}$ for radar, but subsequently continued in a more consistent manner as compared with gauge data. In this figure, the ACCESS 12-24 hr forecast demonstrated a better trend in comparison with three other forecast periods, but timing errors are quite obvious in many instances. Moreover, several events were forecast but were not observed. The ratio of total sum of gauge measuerments to total rainfall estimates for radar is 1.22, while for ACCESS is 0.63, 0.70, 0.67 and 0.68 for the four different forecast periods.

\section{CONCLUSION}

This study has compared rainfall estimates from weather radar and numerical weather prediction (NWP) using independent rain gauge measurements in the Murrumbidgee catchment as ground truth. The daily radar rainfall estimates had a probability of detection of 0.75 and a false alarm rate of 0.09 , while values for the ACCESS model were 0.90 and 0.32 respectively. The radar underestimated rainfall with a $-0.65 \mathrm{~mm} /$ day bias and a 4.17 $\mathrm{mm} /$ day RMSE. The study gauge stations are located more than $100 \mathrm{~km}$ from radar and so the bias may be due to the height of the radar beam above the ground $(1600 \mathrm{~m})$ at this distance. However, the radar also had a significant number of missing data (13\% over the 8 months). In contrast, ACCESS had no missing values with a 
bias of $0.64-0.89 \mathrm{~mm} / \mathrm{day}$ and RMSE of 3.39-5.38 mm/day. Radar underestimated the rainfall with the most considerable difference from gauge measurements in March, which had the heaviest rainfalls, suggesting that attenuation had not been adequately corrected. Furthermore, the errors of the four different lead time forecasts produced by ACCESS were greatest in February, March and April. The NWP model outputs used in the study have relatively coarse resolutions $(12 \mathrm{~km})$, with significant errors expected from using a single gauge to estimate the mean hourly rainfall over the pixel. Consequently, the application of radar data in hydrological modelling is limited by the radar coverage, the large amount of missing data, and the relatively poor performance compared to model predictions. However, further studies of both rainfall estimates are recommended. This requires more independent rain gauges, with a range of distances from the radar, to compare areal average of rainfall measured by gauges with the radar data.

\section{ACKNOWLEDGMENTS}

The work presented in this paper was undertaken as part of short-term stream flow forecasting project in the Murrumbidgee catchment funded by CSIRO. We gratefully acknowledge BoM participation in providing us with the radar data and the NWP product as well as OzNet monitoring operators at Monash and Melbourne Universities. Initial setup and maintenance of the OzNet monitoring network was funded by the Australian Research Council (DP0343778, DP0557543, DP0879212) and by the CRC for Catchment Hydrology.

\section{REFERENCES}

ABARES (Australian Bureau of Agricultural and Resource Economics and Sciences) (2011). The impact of recent flood events on commodities. ABARES Special Report, Australia, 1-32.

Biggs, E.M. and Atkinson, P.M. (2011). A comparison of gauge and radar precipitation data for simulating an extreme hydrological event in the Severn Uplands, UK. Hydrological Process, 25, 795-810.

BoM (Bureau of Meteorology) (2010). Operational implementation of the ACCESS Numerical Weather Prediction systems. NMOC Operations Bulletin, 83, 1-34.

Brandes, E.A., Vivekanandan, J. and Wilson, J.W. (1998). A comparison of radar reflectivity estimates of rainfall from collocated radars. Journal of Atmospheric and Oceanic Technology, 16, 1264-1272.

Buytaert, W., Celleri, R., Willems, P., De Bievre, B., Wyseure, G. (2006). Spatial and temporal rainfall variability in mountainous areas: A case study from the south Ecuadorian Andes.Journal of Hydrology, 329, 413-421.

Ghile, Y.B. and Schulze, R.E. (2010). Evaluation of Three Numerical Weather Prediction Models for Short and Medium Range Agrohydrological Applications. Water Resource Management, 24, 1005-1028.

Hay, L.E., Clark, M.P. (2003). Use of statistically and dynamically downscaled atmospheric model output for hydrologic simulations in three mountainous basins in the western United States. Journal of Hydrology, 282, $56-75$.

Kim, B.K., Kim, B.K. and Kim, H.S. (2008). Flood simulation using the gauge-adjusted radar rainfall and physics-based distributed hydrologic model. Hydrological Process, 22, 4400-4414.

Knox, R. and Anagnostou E.N. (2009). Scale Interactions in Radar Rainfall Estimation Uncertainty. Journal of Hydrologic Engineering, 944-953.

McBride, J. and Ebert, E.E. (2000). Verification of Quantitative Precipitation Forecasts from Operational Numerical Weather Prediction Models over Australia. American Meteorological Society, 103-121.

McPhee, J. and Margulis, S.A. (2005). Validation and Error Characterization of the GPCP-1DD Precipitation Product over the Contiguous United States. American Meteorological Society, 441-459.

Merlin, O., Walker, J.P., Kalma, J.D., Kim, E.J., Hacker,J .,Panciera, R., Young, R., Summerell, G., Hornbuckle, J., Hafeez, M., Jackson, T. (2008). The NAFE'06 data set: Towards soil moisture retrieval at intermediate resolution. Advances in Water Resources, 31, 1444-1455.

Russell, B., Williams, E.R.,Gosset, M., Cazenave, F.,Descroix, L., Guy, N.,Lebel, T. Ali, A., Metayer, F. and Quantin, G. (2009). Radar/rain-gauge comparisons on squall lines in Niamey, Niger for the AMMA. Quarterly Journal of The Royal Meteorological Society, 136(s1), 289-303.

Sebastianelli, S., Russo, F., Napolitano, F., and Baldini, L. (2010). Comparison between radar and rain gauges data at different distances from radar and correlation existing between the rainfall values in the adjacent pixels.Hydrology and Earth System Sciences Discussions, 7, 5171-5212.

Villarini, G., Smith, J.A., Baeck, M.L., Mary Lynn a, Sturdevant-Rees, P. and Krajewski, W.F. (2010). Radar analyses of extreme rainfall and flooding in urban drainage basins. Journal of Hydrology, 381, 266-286. 